\title{
The Impact of Scaffolding Techniques on Saudi English-Language Learners' Speaking Abilities
}

\author{
Khalid Mohammed Alwahibee ${ }^{1}$ \\ ${ }^{1}$ Department of English Language and Literature, College of Languages and Translation, Al-Imam Mohammed \\ Bin Saud Islamic University, Riyadh, Saudi Arabia \\ Correspondence: Khalid Mohammed Alwahibee, Department of English Language and Literature, College of \\ Languages and Translation, Al-Imam Mohammed Bin Saud Islamic University, Riyadh, Saudi Arabia. E-mail: \\ alwahibee@hotmail.com
}

Received: January 25, 2019 Accepted: February 18, 2019 Online Published: July 18, 2019

doi:10.5539/ijel.v9n5p37 URL: https://doi.org/10.5539/ijel.v9n5p37

\begin{abstract}
This study investigated the extent to which scaffolding techniques improve Saudi English-language students' speaking abilities. The study's main aims involved determining why most Saudi students do not want to participate in communication tasks and activities and identifying other ways to encourage teachers and students to be more active during speaking classes. A mixed-methods technique, a special rubric, and an attitude questionnaire to collect this study's data were used. The participants included 50 students from Level 3 in the Department of English Language and Literature at the College of Languages and Translation at Al-Imam Mohammed Bin Saud Islamic University. The experiment lasted for 7 weeks. A teacher met with each group for 2 hours per week. The participants were divided into two groups and experimental and a control group of 25 students each. The experimental group used various scaffolding techniques in each session — which allowed the learners to use their existing knowledge, skills, and strategies in several contexts and for many purposes when speaking. The control group received standard speaking instruction, in which the teacher gave the students time to speak freely without intervention. An independent-sample $t$ test for was used of the analysis. The posttest results showed that the experimental group's speaking ability improved after the pretest. Moreover, the posttests' overall results indicated that the experimental group outperformed the control group. This result emphasized the usefulness of using new techniques to teach speaking to nonnative speakers.
\end{abstract}

Keywords: impact, scaffolding, speaking, strategies, techniques

\section{Introduction}

\subsection{Introducing the Problem}

In recent years, speaking English has become an essential element of applicants' curricula vitae in Saudi Arabia. Unfortunately, high school graduates who join English departments at Saudi colleges are often unable to express themselves orally in English, even if they have received high scores on written English exams (Alharbi, 2015; Sarwar, Alam, Husain, Shah, \& Jabeen, 2014). Learning to speak English fluently is thus essential for university students - particularly those majoring in English — as this skill has a great value in the workforce. The ability to speak English well can be measured in terms of the productive speaking skill.

Chaney and Burk (1998) defines speaking as "the process of building and sharing meaning through the use of verbal and non-verbal symbols, in a variety of contexts" (p. 13). Speaking a target language is one of the most challenging and essential modern tasks. In other words, the ability to transfer verbal utterances into meaning is crucial. Florez (1999) states that speaking is "an interactive process of constructing meaning that involves producing, receiving, and processing information" (p. 1).

Listening and speaking courses are some of the most important courses in English-language programs. However, in countries where people do not speak English, learners in such courses encounter many difficulties when speaking in English, even at the end of these courses. Alharbi (2015) observed that an absence of authentic language learning had produced many students with inadequate oral skills. Therefore, teachers in such environments should provide students with new and innovative teaching strategies for developing speaking skills. One of the best-known techniques is called scaffolding. The purpose of this technique is to encourage shy or 
hesitant students to participate in speaking tasks. Scaffolding, therefore, assists students in speaking with their own words.

The current study investigates the usefulness of scaffolding techniques among nonnative English-language learners. The researcher will apply some techniques to help students overcome their shyness, hesitation, and lack of vocabulary. It is expected that these techniques would help students interact positively in class discussions.

\subsection{Statement of the Problem}

Many researchers found that high school graduates could not speak English appropriately (Alharbi, 2014; Alonso, 2014). As a result, those students join colleges' English departments, they face difficulty in expressing themselves in English despite the fact that they take two semesters of English courses during the preparatory years which are required by the English Department. Unfortunately, most teachers of speaking courses strictly follow their textbooks, which do not provide strategies that help students improve their speaking abilities. Saudi students who join English departments have problems with practicing their speaking skills and need to be encouraged to speak and participate through the use of new techniques. As Alharbi (2015) states, many factors negatively affect speaking among Saudi students: the students' use of their native language with their peers outside and inside the classroom, the country's low interest in speaking English, the students' negative attitudes about learning English, and the teachers' extensive use of Arabic in class. In addition, some students are not willing to communicate in English. Based on these assumptions and my observations, I have determined that most low- to intermediate-level students are hesitant and shy when communicating in English. The determination of this problem led to this investigation of possible ways to encourage these students and change their views and attitudes about communicating during speaking classes.

\subsection{Purpose of the Study}

The purposes of this study are three folds: (a) to find out why most Saudi students do not want to participate in communication tasks and activities, (b) to identify new techniques to encourage teachers and students to be more active during speaking classes, and (c) to investigate how the use of scaffolding techniques affects Saudi students' speaking abilities.

\subsection{Research Questions}

This study's research questions are as follows: (a) To what extent do scaffolding techniques improve the speaking abilities of Saudi English-language students? (b) What are the students' attitudes toward the use of scaffolding techniques in speaking classes?

\section{Literature Review}

Jerome Burner, a cognitive phycologist, introduced a teaching technique called scaffolding theory in the late 1950s based on his observations to how parents helped their infants to speak their first words. However, the idea behind this technique sprung from a theory that was developed by the Soviet psychologist and social constructivist Lev Vygotsky (1896-1934), which is known as the zone of proximal development. Raymond (2000) defines this zone as "the distance between what children can do by themselves and the next learning that they can be helped to achieve with competent assistance" (p. 176). Raymond (2000), defines scaffolding as the "role of teachers and others in supporting the learners' development and providing support structures to get to that next stage or level" (p. 176). Scaffolding has a temporary effect that lasts only until students master a skill, after which, it disappears gradually. Gibbons (2002) noted that the name of the scaffolding technique is derived from the name of a temporary structure that is used when constructing a building; when the building is almost complete, the scaffolding is removed. With scaffolding, students should be able to master the concept and complete related tasks independently (Chang, Chen, \& Sung, 2002).

The goal of scaffolding, according to Alshumaimeri and Almasri (2012), is to provide special help so that learners can move on to new skills, concepts, and levels of understanding. In addition, Hartman (2002) emphasizes that the goal of scaffolding techniques is to help students become independent and self-regulated learners and problem solvers. The use of scaffolding encourages learners to become more active and engage in the learning process; this leads them to make personal connections during that process. Another goal of this technique is to develop learners' critical-thinking skills and autonomy. Henry (2002) confirms these goals and emphasizes that the most significant goal of teaching is to convert students into independent, self-regulatory learners.

Teachers use many types of scaffolding techniques in education. The type of scaffolding used depends on the types of activities performed during a given class, as each activity has scaffolding. Roehler and Cantlon (1997) suggest five types of scaffolding techniques. The first type involves providing students with an explanation to 
help them learn. The second type involves encouraging them to participate by presenting them with various types of activities. The third type involves the think-aloud protocol, which involves presenting a model to the students. The fourth type involves checking on students' emerging understanding and providing feedback if necessary. The last type involves engaging students by giving them the clues that they need to solve problems.

Some researchers found positive effects of using scaffolding techniques in teaching various language skills. Walton and Archer (2004) investigated the effectiveness of scaffolding through the use of Web resources in a project-based curriculum among students at an engineering college. The results showed a connection between the development of academic knowledge and discourse and the successful academic use of Web resources. Zarandi and Rahbar (2016) investigated scaffolding strategies' effects on the speaking abilities of Iranian learners of English as a foreign language (EFL) and found that these strategies successfully enhanced the learners' speaking abilities. Moreover, Ginaya, Rejeki and Astuti (2018) found that scaffolding techniques can be used to improve students' speaking abilities. Scaffolding has proven useful in developing students' listening skills as well. Talebinejad and Akhgar (2015) confirmed that teachers' scaffolding has a significant impact on learners' listening achievements.

\section{Methodology}

\subsection{Participants}

The population of this study included English-language students from the Department of English and Literature within the College of Languages and Translation at Al-Imam Mohammed Bin Saud Islamic University in Saudi Arabia. A sample of 50 Level 3 students voluntarily participated (see Appendix A for the consent form). Before engaging in the study, all the participants had completed two courses on listening and speaking (Levels 1 and 2). Their ages range from 20 to 22 years old. All participants speak Arabic as a native language and finished the preparatory years. To enroll in the English department, a student should get at least a 55 out of 100 in the standardized test for English proficiency that the National Center for Assessment administers to measure students' English skills. In addition to this speaking course, the participants took courses on other areas of the English language - including reading comprehension, writing skills, and English grammar-and some Arabic courses.

\subsection{Research Instruments}

This experimental study is designed to determine scaffolding techniques' effect on students' speaking abilities. Therefore, a mixed-methods technique for the analysis in this study was used. Also, a pretest, posttest, and a questionnaire on the students' attitudes were introduced. This study adopts pretest-posttest steps from the Cambridge preliminary test, which includes three types of interview questions. The first type comprises short questions that each student answers quickly by providing personal information or facts. To answer the second type of question, each student examines a picture or a topic and then discusses it with another student. Finally, the students speak at length (i.e., for $1 \mathrm{~min}$ ) about a photograph. A special rubric was constructed that addresses four factors: fluency, choice of vocabulary, comprehension, and grammar (see Appendix B). The other examiner-who happened to be teaching the same course - and the researcher used this rubric to score each item in each interview; for each student and compiled the average of the total scores in the score sheet.

An attitude questionnaire is used. It contained 10 statements. The students responded using a 5-point Likert scale that ranged from 1 (strongly disagree) to 5 (strongly agree; see Appendix C). The questionnaire's purpose was to determine the extent to which the students liked to use the scaffolding strategies and their attitudes about the effect that those strategies had on their performances in class.

\subsection{Pretest-Posttest Interview Questions and the Evaluation Rubric}

Validity. The researcher distributed the prepared questions for the pretest and posttest to two professors and a lecturer previously taught speaking classes several times. All agreed that the questions are suitable and that they would encourage students to speak in the target language, either individually or in groups.

The evaluators suggested that an extra item to be added—pronunciation and content- to the evaluation rubric to comply with Knight's (1992) classification of the elements of speaking. The updated rubric evaluated the following categories: fluency, choice of vocabulary, comprehension, grammar, pronunciation, and content.

Reliability. To ensure that the rubric was appropriate for scoring, the researcher interviewed six students and practiced the evaluation process. The other examiner and the researcher exhibited almost the same grading criteria; the recorded scores indicated agreement between both. 


\subsection{Attitude Questionnaire.}

Validity. The attitude questionnaire was distributed to two professors and a lecturer who previously taught speaking classes several times. All agreed that the statements were suitable. They suggested that some grammatical and stylistic mistakes based to be corrected. One of the evaluators suggested that the original statement 9 ("Scaffolding is a waste of class time") should be deleted; the other two evaluators did not initially mention anything about this issue, but after discussing this with the researcher. the evaluators and the researcher agreed that it should be deleted.

Reliability. The same six students who were interviewed for the rubric judged the attitude questionnaire to determine the statements' clarity. Their general opinions were measured about the use of various scaffolding techniques in speaking classes. They showed an interest in the technique and liked it. Moreover, the researcher explained the meaning and types of scaffolding to the pilot study's students. Then they were asked to reply to the questionnaire items. Cronbach's alpha was calculated (see Table 1).

Table 1. Cronbach's Alpha for the attitude questionnaire

\begin{tabular}{lll}
\cline { 2 - 2 } Reliability statistics & & \\
\cline { 2 - 4 } Statements & $\alpha$ & No. of Items \\
Attitude & .793 & 9 \\
\hline
\end{tabular}

Note. $\alpha=.793$ is statistically acceptable.

\subsection{Procedures}

All 50 participants expressed an interest in improving their speaking abilities. After all, fifty participants signed the consent form, they were divided into two groups. The experimental group met every Monday from 1:00 p.m. to 3:00 p.m., and the control group met every Tuesday from 1:00 p.m. to 3:00 p.m. The experiment lasted for 7 weeks. In the first week, both groups received clear descriptions about how the classes would be. At the beginning of this research, the examiner and the researcher interviewed all the students to determine their speaking levels using an evaluation rubric (see Appendix B). During the next 5 weeks, the control group studied speaking with traditional teaching strategies and techniques; their teacher divided their class into four groups, and each group was assigned a topic to talk about, with 15 minutes for preparation. Afterward, each group spoke about its assigned topic; each student in the group spoke at least one sentence. The teacher did not correct any of the students' mistakes in terms of grammar, pronunciation, word choice, or content. The teacher's role was that of a listener - even when the students exhibited trembling, hesitation, or wrong expressions. The teacher became involved only when students asked for help. Some of the assigned topics were Saudi women's driving, the importance of new social media programs, smartphone use among children under 18 years old, and the benefits and drawbacks of video games.

The same process was applied to the experimental group: The class had four groups, and they discussed the same topics as the groups in the control class. However, the teacher gave pairs of groups the same topic, with one group was arguing for a position and the other was arguing against it. The teacher intervened with these groups and used a variety of scaffolding techniques to help every student in the experimental group to speak. For one of the topics, the teacher asked the members of the groups to role-play a script. He explained that strategy to the students. For the second group, the teacher assisted the student to do the activity by using the think-aloud protocol. In other words, he showed the students how to think about their topic. In another session, the teacher presented a model for each group by demonstrating the sentences or phrases for the students. Sometimes, the teacher provided feedback for every student in the group by supplying English words, phrases, or even completes sentences for the students to finish the tasks. In later sessions, the teacher told the participants what they should talk about and concentrate on. This helped the group to narrow their focus. The scaffolding techniques that the teacher used varied across the 7 weeks of the experiment. In short, the researcher varied the use of the techniques. One technique was show and tell, in which students examined and discussed a series of pictures. Another technique involved asking them to read about a topic before coming to class. In one interesting technique, the students talked about a topic that they knew something about (e.g., soccer teams). At other times, the teacher handed each group a list of words related to the assigned topic. The teacher also assisted the speakers by posting questions that the speaker should answer during his or her speech. During the last session, the teacher interviewed the students for the posttests. 


\section{Data Analysis}

Because this is an experimental study, both quantitative and qualitative analyses are used. However, before conducting the analyses, the Pearson-product correlation was calculated to confirm the interrater reliability of both groups' scores for the pretest, which was administered to all participants to determine their speaking levels, and posttest.

To ensure that the groups had no significant differences in their speaking levels, an independent-sample $t$ test was conducted before the experiment. Table 2 shows the results.

Table 2. Independent-sample t-test results for the pretests

\begin{tabular}{lllllll}
\hline Test & Group & $n$ & $M$ & $S D$ & $t$ & Significance level (2-tailed) \\
\hline Pre & Control & 20 & 36.85 & 1.814 & .411 & .683 \\
& Experimental & 25 & 36.60 & 2.179 & & \\
\hline
\end{tabular}

The pretest means were 36.85 for the control group and 36.60 for the experimental group. There were no significant differences between the two groups, as the significance was .683 , which is greater than .05 . For the pretest, $t=.0411$. The two groups thus were equal in speaking level at the time of the pretest. A Pearson-product correlation was used to confirm the interrater reliability for both tests. Table 3 shows the results.

Table 3. The interrater reliability for both groups' results on both tests

\begin{tabular}{|c|c|c|c|c|c|c|}
\hline \multirow[t]{3}{*}{ 1st examiner } & & \multirow[t]{3}{*}{ Measure } & \multicolumn{4}{|c|}{ 2nd examiner } \\
\hline & & & \multicolumn{2}{|c|}{ Control group } & \multicolumn{2}{|c|}{ Experimental group } \\
\hline & & & Pretest & Posttest & Pretest & Posttest \\
\hline \multirow[t]{6}{*}{ Control group } & Pretest & Pearson correlation & .553 & & & \\
\hline & & Sig. (2-tailed) & .011 & & & \\
\hline & & $n$ & 20 & & & \\
\hline & Posttest & Pearson correlation & & .616 & & \\
\hline & & Sig. (2-tailed) & & .004 & & \\
\hline & & $n$ & & 20 & & \\
\hline \multirow[t]{6}{*}{ Experimental group } & Pretest & Pearson correlation & & & .685 & \\
\hline & & Sig. (2-tailed) & & & $<.001$ & \\
\hline & & $n$ & & & 25 & \\
\hline & Posttest & Pearson Correlation & & & & .898 \\
\hline & & Sig. (2-tailed) & & & & $<.001$ \\
\hline & & $n$ & & & & 25 \\
\hline
\end{tabular}

For the pretest of the control group, $r=.553$, and the two examiners' results had a significant relationship at the .05 level (significance level $=.011$ ). For the posttest of the control group, $r=.616$, and the two examiners' results had a significant relationship at the .05 level (significance level $=.004$ ). For the pretest of the experimental group, $r$ $=.685$, and the two examiners' results had a significant relationship at the .01 level (significance level $<.001$ ). For the posttest of the experimental group, $r=.898$, and the two examiners' results had a significant relationship at the .01 level (significance level $<.001$ ). These results indicate that the interrater reliability is highly significant.

\subsection{Examine the Hypotheses}

To examine the results of the study's research questions, few hypotheses were created.

\subsubsection{First Hypothesis}

For the posttest, the mean scores of the control and experimental groups lacked a significant difference $(\alpha \leq .05)$ and thus showed no significant effect of using scaffolding techniques.

To test this hypothesis, an independent-sample $t$ test was performed to identify any significant differences in the two groups' mean scores. Also, $\eta^{2}$ was used to measure the scaffolding techniques' effect on the development of speaking ability in the experimental group compared to the control group (see Table 4). 
Table 4. Independent-sample t-test results for the posttests

\begin{tabular}{llllllll}
\hline Test & Group & $n$ & $M$ & $S D$ & $t$ & Sig. (2-tailed) & $\eta 2$ \\
\hline Post & Control & 20 & 42.80 & 1.908 & 10.650 & .000 & .725 \\
& Experimental & 25 & 52.36 & 3.627 & & & \\
\hline
\end{tabular}

The mean posttest scores were 42.80 for the control group and 52.36 for the experimental group. The control and the experimental groups' posttest scores had a significant difference at the .05 level, as the significance was $<.001$. For the posttest, $t=10.65$. Using scaffolding techniques thus had a positive effect on the development of speaking abilities in the experimental group compared to those of the control group. As $\eta^{2}=.725$, the effect was of a high level-as classified by Hassan (2011), who stated that an effect is high if $\eta^{2}>.14$. Therefore, this result indicates that the scaffolding technique had a strong positive effect on the students' speaking levels.

\subsubsection{Second Hypothesis}

The control group's mean scores on the speaking pretest and posttest lacked a significant difference $(\alpha \leq .05)$.

To test this hypothesis, a paired-sample test was conducted for the control group to investigate whether the students' speaking abilities would have any significant differences across the tests (see Table 5).

Table 5. Paired-sample results for differences in the control group's mean scores across tests

\begin{tabular}{llllllll}
\hline Group & Test & $n$ & $M$ & $S D$ & $t$ & $d f$ & Significance level. (2-tailed) \\
\hline Control & Pre & 20 & 36.85 & 1.814 & 17.698 & 19 & .000 \\
& Post & 20 & 42.80 & 1.908 & & & \\
\hline
\end{tabular}

The mean scores for the control group were 36.85 on the pretest and 42.80 for the posttest. The control group's mean scores across the tests had significant differences at the .05 level, as the significance was $<.001$. For the control group, $t=17.698$. The traditional way of teaching had a positive effect on the control group's speaking abilities, resulting in a $16.1 \%$ improvement.

\subsubsection{Third Hypothesis}

The experimental group's mean scores on the speaking pretest and posttest lacked a significant difference ( $\alpha$ $\leq .05)$.

To test this hypothesis, a paired-sample test was conducted for the experimental group to investigate whether the students' speaking abilities had any significant differences across the tests (see Table 6).

Table 6. Paired-sample results for differences in the experimental group's mean scores across tests

\begin{tabular}{llllllll}
\hline Group & Test & $n$ & $M$ & $S D$ & $t$ & $d f$ & Significance level. (2-tailed) \\
\hline Experimental & Pre & 25 & 36.60 & 2.179 & 32.795 & 24 & .000 \\
& Post & 25 & 52.36 & 3.627 & & & \\
\hline
\end{tabular}

The mean scores for the experimental group were 36.00 on the pretest and 52.36 on the posttest. The experimental group's mean scores had significant differences at the 0.05 level across tests, as the significance was $<.001$. For the experimental group, $t=32.795$. The use of scaffolding techniques had a positive effect on the experimental group's development of speaking abilities, resulting in a $43.1 \%$ improvement.

\subsubsection{Fourth Hypothesis}

The experimental group did not have a positive attitude about the use of the scaffolding technique.

To test this hypothesis, the mean scores and standard deviations were calculated, using Likert-scale responses that ranged from 1 (strongly disagree) to 5 (strongly agree). Table 7 shows the classifications of the mean Likert-scale scores. 
Table 7. Score classifications for mean scores of the questionnaire items

\begin{tabular}{ll}
\hline Direction & $M$ \\
\hline Very high & $4.20-5.00$ \\
High & $3.40-4.20$ \\
Medium & $2.60-3.40$ \\
Low & $1.80-2.60$ \\
Very low & $1.00-1.80$ \\
\hline
\end{tabular}

Table 8. The experimental group's attitudes toward the scaffolding techniques

\begin{tabular}{llllll}
\hline Statement & $N$ & $M$ & $S D$ & Rating & Ranking \\
\hline S4 & 25 & 4.48 & 0.918 & Strongly Agree & 1 \\
S6 & 25 & 4.20 & 1.080 & Strongly Agree & 2 \\
S2 & 25 & 4.16 & 0.987 & Agree & 3 \\
S3 & 25 & 3.96 & 1.020 & Agree & 4 \\
S1 & 25 & 3.92 & 1.222 & Agree & 5 \\
S9 & 25 & 3.92 & 1.222 & Agree & 5 \\
S5 & 25 & 3.72 & 1.339 & Agree & 7 \\
S7 & 25 & 3.40 & 1.258 & Agree & 8 \\
S8 & 25 & 2.04 & 0.935 & Disagree & 9 \\
Total & 25 & 3.96 & 0.518 & Agree & \\
\hline
\end{tabular}

\section{Discussion}

The findings of this study are in line with those of other studies on scaffolding techniques' effect on the development of speaking ability for EFL students. This study's findings mirror those of Zarandi and Rahbar (2016), who found that the participating students' overall speaking abilities improved very significantly after the students were introduced to scaffolding techniques and were trained to use them in class. Similarly, this study's findings are in line with those of Ginaya et al. (2018), who found a significant positive difference for the experimental group compared to the control group - indicating that the implementation of scaffolding techniques improved the participating students' speaking abilities. In this study, it was noticed that the overall mean posttest scores were higher in the experimental group than in the control group, which indicates that the use of scaffolding techniques was successful.

Scaffolding techniques have proven to be useful in teaching language skills other than the ones discussed in this study. Yelland and Masters (2007), for instance, found that teachers' use of scaffolding techniques as teaching tools helped students to learn language skills such as listening and speaking. Similarly, Mehrani and Modarresi (2011) found that the use of scaffolding improved the general English proficiency of EFL learners. Moreover, Swain and Lapkin (2001) investigated the use of students' mother tongues as a scaffolding technique and found that it triggered the thinking process among learners and improved their second-language abilities.

In this study, although both groups showed a kind of improvement, the experimental group showed a much larger improvement (43.1\%) than the control group (16.1\%) did. In addition, it was found that the intervening scaffolding strategies had a significant positive effect on the development of speaking skills among EFL students.

The experimental-group students showed positive attitudes toward the use of scaffolding techniques as a teaching strategy, according to their responses to the attitude questionnaire (see Table 8). Most of the responses fell on the positive side of the continuum, with the answers for eight of the statements averaging between 2.60 and 5 on the Likert scale from 1 to 5 ; only one statement fell on the negative side of the continuum. However, when considering the responses, they can also be discussed in light of their importance to the students. Item 4 ("I will not hesitate to participate in English conversations") ranked first in importance, which indicated that students liked how the techniques were useful in helping them to not feel shy. Because they found the techniques to be useful, they selected Item 6 ("Teachers of speaking courses should use these techniques") as the second most important. They also reported that the scaffolding teaching strategies made them very confident, so they rated item 2 as the third most important. In addition, the students found that learning with many scaffolding techniques helped them become better learners, so they ranked Item 3 as the fourth most important. On the other hand, the students ranked Item 8 ("This technique will be very useful in other courses") as the least important. This could be interpreted as the students saying that they cannot judge the usefulness of the technique in other applications until they have tried using it in those applications. As such, this judgment is left for people in specialized roles, such as researchers and teachers. Generally, the students showed a positive attitude toward using scaffolding as a learning tool to improve 
their speaking skills.

\subsection{Answering Research Questions}

The answers to the research questions are as follows.

\subsubsection{First Question}

To what extent do scaffolding techniques improve the speaking abilities of Saudi English-language students?

The statistical analysis indicated that the experimental group improved from the pretest to the posttest by $43.1 \%$. Although the control group showed some improvement as well (16.1\%), the experimental group improved more.

\subsubsection{Second Question}

What are the students' attitudes toward the use of scaffolding techniques in speaking classes?

The analysis of the attitude questionnaire revealed that most of the students' responses were positive. This indicates that the students believed that they benefited from using scaffolding techniques in their speaking classes.

\subsection{Recommendations}

The research results suggest that teachers should know the correct type of strategies for various exercises to enhance their students' learning. In particular, they need to know what types of scaffolding techniques they should use in speaking classes. Educators and English-program developers should include techniques in the curricula to train students on these scaffolding techniques. This will save time for teachers by summarizing the information and content for the students. Also, teachers should teach scaffolding techniques explicitly to ensure that the learners are aware of how to use them inside and outside classrooms.

Teachers should not confine themselves to the techniques mentioned in this study, as many other techniques can be useful when teaching speaking skills. Teachers also need to consider that any speaking techniques can have a positive effect, as even the traditional way of teaching had some kind of positive effect on students' achievement in this study.

\subsection{Suggestions for Further Research}

Based on the results of this research, it is recommended that some researchers replicate this study with a focus on other English-language skills to determine whether scaffolding techniques have the same effect on Saudi EFL students' achievement in those skills. A comparison of male and female students in this context would also be a good topic for further study. Moreover, it is recommended to test the effect of this technique with students of different levels to search for any differences and investigating this technique with a large number of participants so that the researchers will be able to generalize the results. The results also suggest comparing the effect of using scaffolding technique in teaching other skills of English language skills to nonnative English speakers.

\section{References}

Alharbi, H. (2015). Improving students' English speaking proficiency in Saudi public schools. International Journal of Instruction, 8(1), 105-116. https://doi.org/10.12973/iji.2015.818a

Alonso, R. A. (2014). Teaching speaking: An exploratory study in two academic contexts. Porta Linguarum, 22, $145-160$.

Alshumaimeri, A., \& Almasri, M. (2012). The effects of using WebQuests on reading comprehension performance of Saudi EFL students. The Turkish Online Journal of Educational Technology, 11(4), 295304.

Chaney, A. L., \& Burk, T. L. (1998). Teaching oral communication in grades K-8. Boston, MA: Allyn \& Bacon.

Chang, K., Chen, I., \& Sung, Y. (2002). The effect of concept mapping to enhance text comprehension and summarization. The Journal of Experimental Education, 71(1), 5-23. https://doi.org/10.1080/00220970209602054

Florez, M. A. C. (1999). Improving adult English-language learners' speaking skills. Washington, DC: Clearinghouse for ESL Literacy Education.

Gibbons, P. (2002). Scaffolding language, scaffolding learning: Teaching second language learners in the mainstream classroom. Portsmouth, NH: Heinemann.

Ginaya, G., Rejeki, I., \& Astuti, N. (2018). The effects of blended learning to students' speaking abilities. International Journal of Linguistics, Literature and Culture, 4(3), 1-14. https://doi.org/10.21744/ijllc.v4i3.661 
Hartman, H. (2002). Scaffolding and cooperative learning: Human learning and instruction. City, NY: College of City University Press of New York.

Hassan, I. (2011). Psychological and educational statistics: Application using SPSS 18 program. Cairo, Egypt: Dar Alfikr Alarabi.

Knight, B. (1992). Assessing speaking skills: A workshop for teacher development. ELT Journal, 46(3), 294302. https://doi.org/10.1093/elt/46.3.294

Mehrani, M. B., \& Modarresi, G. (2011). The nature of interactive and intervening strategies in scaffolding EFL reading skill. The Iranian EFL Journal, 7(1), 116-126.

Raymond, E. (2000). Learners with Mild Disabilities. Needham Heights, MA: Allyn \& Bacon.

Roehler, L. R., \& Cantlon, D. J. (1997). Scaffolding: A powerful tool in social constructivist classrooms. In K. Hogan \& M. Pressley (Eds.), Scaffolding student learning: Instructional approaches and issues (pp. 6-42). Cambridge, MA: Brookline.

Sarwar, M., Alam, M., Husain, A., Shah, A., \& Jabeen, M. (2014). Assessing English speaking skills of prospective teachers at entry and graduation level in teacher education program. Language Testing in Asia, 4(1), 1-9. https://doi.org/10.1186/2229-0443-4-5

Swain, M., \& Lapkin, S. (2001). Focus on form through collaborative dialogue: Exploring task effects. In M. Bygate, P. Skehan \& M. Swain (Eds.), Researching pedagogic tasks: Second language learning, teaching and testing. Harlow, England: Longman.

Talebinejad, M. R., \& Akhgar, F. (2015). The impact of teacher scaffolding on Iranian international EFL learner's listening comprehension achievement. Theory and Practice in Language Studies, 5(5), 1101-1110. https://doi.org/10.17507/tpls.0505.27

Tyas, D. (2012). Teachers' scaffolding talks in teaching speaking. Unpublished master's thesis, Semarang State University, Indonesia.

Yelland, N., \& Masters, J. (2007). Rethinking scaffolding in the information age. Computers \& Education, 48, 362-382. https://doi.org/10.1016/j.compedu.2005.01.010

Zarandi, S., \& Rahbar, B. (2016). Enhancing speaking ability through intervening scaffolding strategies. Theory and Practice in Language Studies, 6(11), 2191-2195. https://doi.org/10.17507/tpls.0611.17

\section{Appendix A}

\section{Participation Consent Form}

I, ........, hereby declare my interest in participating in this research study for a paper entitled "Using Scaffolding Techniques to Enhance Saudi EFL Learners' Speaking Ability." I am well aware that I could be assigned to either the control or experimental group. I give the researcher full authority to reveal this study's results. Therefore, I sign this consent form with full understanding of my rights.

Participant's name:

Participant's signature:

\section{Appendix B}

\section{Evaluation Rubric}

\begin{tabular}{|c|c|c|c|c|c|c|c|c|}
\hline \multirow{2}{*}{$\begin{array}{l}\text { Studen } \\
\mathrm{t}\end{array}$} & \multirow[t]{2}{*}{ Examiner } & \multicolumn{7}{|c|}{ Evaluation elements ( 10 points each) } \\
\hline & & Vocabulary & Comprehension & Fluency & Grammar & Pronunciation & Content & Total \\
\hline \multirow[t]{3}{*}{1} & First & & & & & & & \\
\hline & Second & & & & & & & \\
\hline & Mean & & & & & & & \\
\hline
\end{tabular}




\section{Appendix C}

\section{Attitude Questionnaire}

\begin{tabular}{|c|c|c|c|c|c|c|}
\hline No. & Statement & Strongly agree & Agree & Neutral & Disagree & Strongly disagree \\
\hline 1 & Scaffolding is very interesting. & & & & & \\
\hline 2 & $\begin{array}{l}\text { I feel confident when speaking with others } \\
\text { because of this course. }\end{array}$ & & & & & \\
\hline 3 & $\begin{array}{l}\text { I learned many ways to encourage myself to } \\
\text { speak. }\end{array}$ & & & & & \\
\hline 4 & I will not hesitate to participate in conversations. & & & & & \\
\hline 5 & $\begin{array}{l}\text { In-class scaffolding helped me to develop my } \\
\text { speaking. }\end{array}$ & & & & & \\
\hline 6 & Teachers of speaking should use these techniques. & & & & & \\
\hline 7 & $\begin{array}{l}\text { My friends and I were active in this speaking } \\
\text { class. }\end{array}$ & & & & & \\
\hline 8 & $\begin{array}{l}\text { This technique will be very useful in other } \\
\text { courses. }\end{array}$ & & & & & \\
\hline 9 & $\begin{array}{l}\text { Active teachers can have positive effects on } \\
\text { students' speaking abilities. }\end{array}$ & & & & & \\
\hline
\end{tabular}

\section{Copyrights}

Copyright for this article is retained by the author, with first publication rights granted to the journal.

This is an open-access article distributed under the terms and conditions of the Creative Commons Attribution license (http://creativecommons.org/licenses/by/4.0/). 